\title{
Hysterectomy for Uterine Inversion: About Two Cases at University Hospital of Cocody (Abidjan-Ivory Coast)
}

\author{
Roland Adjoby ${ }^{1}$, Charles Kakou ${ }^{*}$, Arthur Kouame1, N'da Kouame², Didier Abouna ${ }^{2}$, \\ Joachim Konan', Denis Effoh ${ }^{1}$, Christian Alla1, Ibrahima Balde ${ }^{3}$ \\ ${ }^{1}$ Gynecology and Obstetrics Department, University Hospital of Cocody, Abidjan, Ivory Coast, Côte d'Ivoire \\ ${ }^{2}$ Pathology Department, University hospital of Cocody, Abidjan, Ivory Coast, Côte d'Ivoire \\ ${ }^{3}$ Gynecology and Obstetrics Department, University Hospital Ignace Deen of Guinea, Conakry, Guinea \\ Email: *kakoucharles@yahoo.fr
}

How to cite this paper: Adjoby, R., Kakou, C., Kouame, A., Kouame, N., Abouna, D., Konan, J., Effoh, D., Alla, C. and Balde, I. (2018) Hysterectomy for Uterine Inversion: About Two Cases at University Hospital of Cocody (Abidjan-Ivory Coast). Open Journal of Obstetrics and Gynecology, 8, 368-375. https://doi.org/10.4236/ojog.2018.84041

Received: February 10, 2018

Accepted: April 14, 2018

Published: April 17, 2018

Copyright $\odot 2018$ by authors and Scientific Research Publishing Inc. This work is licensed under the Creative Commons Attribution International License (CC BY 4.0).

http://creativecommons.org/licenses/by/4.0/

\begin{abstract}
It is a rare clinical condition that may occur to two possible types: puerperal uterine inversion (IUP) and no puerperal uterine inversion (IUNP). Obstetrician will observe often only once in his professional practice. The risk of maternal mortality by hemorrhage is high. We report two cases of uterine inversion requiring a hysterectomy, including a postpartum mode and the other gynecological mode with young women. Hysterectomy remained a last resort treatment in the two types, to reduce morbidity. In the case of uterine inversion, the treatments without hysterectomy could be facilitated if the management is early and adequate. Furthermore, the support should be multidisciplinary and fast in the two types.
\end{abstract}

\section{Keywords}

Uterine Inversion, Delivery Hemorrhage, Uterine Fibroma, Hysterectomy

\section{Introduction}

The uterine inversion is a complication which is defined as an invagination of the uterine substance to "glove finger", which can go up to its externalization to the vulva [1] [2]. It's a rare situation described in two forms according to Jones: postpartum or not postpartum [3]. The most important aspect of this disease is early diagnosis for a better prognosis. The puerperal uterine inversion (IUP) has his prognosis strongly linked to the immediate recognition of the inversion; this allows avoiding hysterectomy, even maternal death [1]. In the case of uterine 
inversion no postpartum (IUNP), the diagnosis is easy in its full form, however the contribution of imagery is a help to diagnose the incomplete forms [3]. From theses 2 cases of uterine inversion (postpartum and no postpartum) and a literature review, we discuss the place of hysterectomy as surgical treatment of last resort.

\section{Observation No. 1}

Madam T.S, 31 years old, African, primiparous primigravida, having no medical history, was admitted to the obstetrical emergencies of university hospital of Cocody (Abidjan) for massive bleeding of the immediate postpartum and pelvic pain. History found a vaginal delivery in a maternity, level I, dating back to three (3) hours, and the newborn weighing $3100 \mathrm{~g}$ with Apgar score to 9 at 5 minutes of live. Gestational age was 38 weeks of amenorrhea and 2 days. We found in the labor history the notion of excessive uterine expression at the time of the expulsion fetal. The labor occurred after seven (7) hours. At the time of admission, the patient was rough, in state of shock, blood pressure to $80 / 60 \mathrm{mmHg}$, pulse racing 120 beats per minute. Suprapubic palpation objectified the absence of uterus in the hypogastric region. Physical examination using vaginal valve showed a large soft mass at big bottom and corresponding to the uterine substance. The diagnosis of postpartum uterine inversion of 2 nd degree is referred to. After several manual reduction failed three times, it was immediately decided a reduction during an emergency laparotomy (see Picture 1). The technique of progressive reduction by blunt clips according to the technique of Huntington has not been effective. A hysterectomy for hemostasis has so decided and conducted as a last recourse for maternal rescue. The patient received a blood transfusion of three (3) units globular to stabilize hemodynamic. The histological examination objectified several areas of infarction (see Figure 1 and Figure 2). At the admission, hemoglobin rate was $5.5 \mathrm{~g} / \mathrm{dl}$. At the postoperative time, it had been observed an anemia moderate to $7.2 \mathrm{~g} / \mathrm{dl}$. The patient was reviewed 15 days after leaving the hospital, for a control.

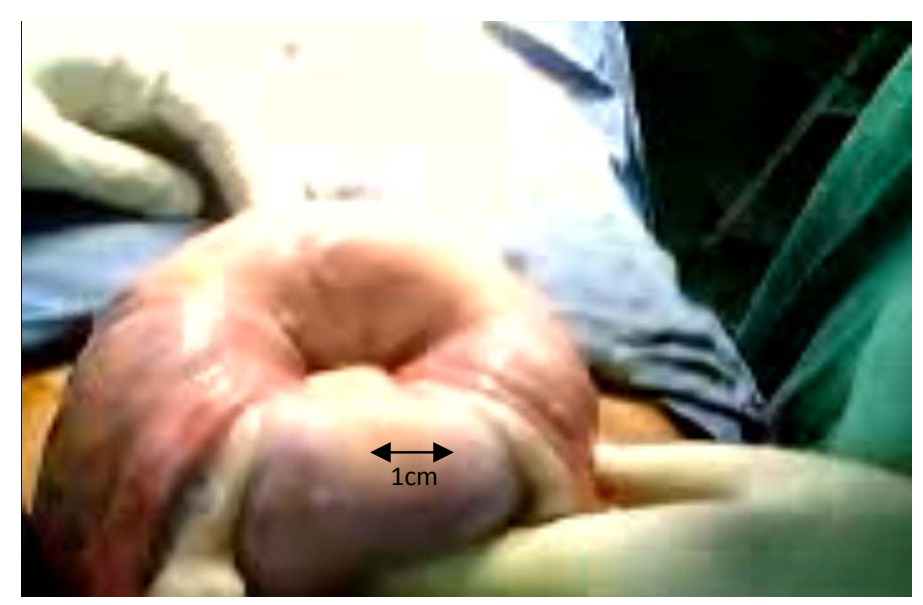

Figure 1. Uterus after attempt of manual reduction of uterine inversion. 


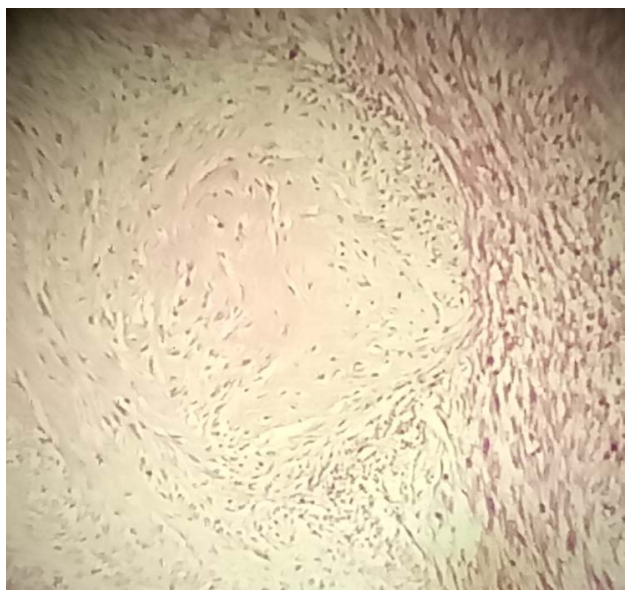

Figure 2. $(\mathrm{HE} \times 25)$ Several areas of infarction objectified on the histological examination (cf Dr Abouna Didier ${ }^{\star}$ Pathology department University hospital of Cocody/Abidjan).

\section{Observation No. 2}

It was a woman second gravida, primiparous, 28 years old, african. In its history, include chronic pelvic pain, pelvic heaviness and intermittent vaginal bleeding during 6 months for which she had received medical treatment without success. Admission to gynecological emergencies, she felt a vaginal mass accompanied by an intense urge to push. A thrust, a large fleshy mass is enacted at the vulva. Pelvic examination revealed a bilobed firm mass depending of the uterus (see Figure 3). The proximal was pink and measured $15 \mathrm{~cm}$ in diameter, while the distal blackish measured $10 \mathrm{~cm}$ in diameter. The cervix was not visible. The bimanual examination found a high collar located in the pelvic while the body of the uterus was not palpable. A pelvic ultrasound did not identify the uterus in the pelvic area. Uterine inversion caused by a uterine tumor has been diagnosed. After preoperative support, abdominal hysterectomy was performed after the excision vaginal tumor in the first time. Histological examination (see Figure 4) was in favour of a sub-mucosal leiomyoma in the bottom of the uterus. Patient examination at $15^{\text {th }}$ post operative day was normal.

\section{Discussion}

\subsection{Epidemiology}

The frequency of uterine inversion reported in the literature is highly variable. It would be 1/100,000 in Europa and 1/2000 in United States [1] [2] [4]. The variability of the frequency can be explained by the unusualness of this pathology. In Côte d'Ivoire, there is no data on this pathology. Two conditions are necessary for the occurrence of a uterine inversion: uterine hypotonia and sufficient cervical dilatation [5]. The puerperal uterine inversion (IUP) of obstetric origin in $85 \%$ to $95 \%$ of cases [1] [6], committed life-threatening maternal and requires a fast support. It is described 4 anatomical stages of increasing severity [7]. The stage I contain the uterine background in cup without reaching the cervical orifice. At the stage II, the uterine substance crosses the cervical orifice. At the stage 


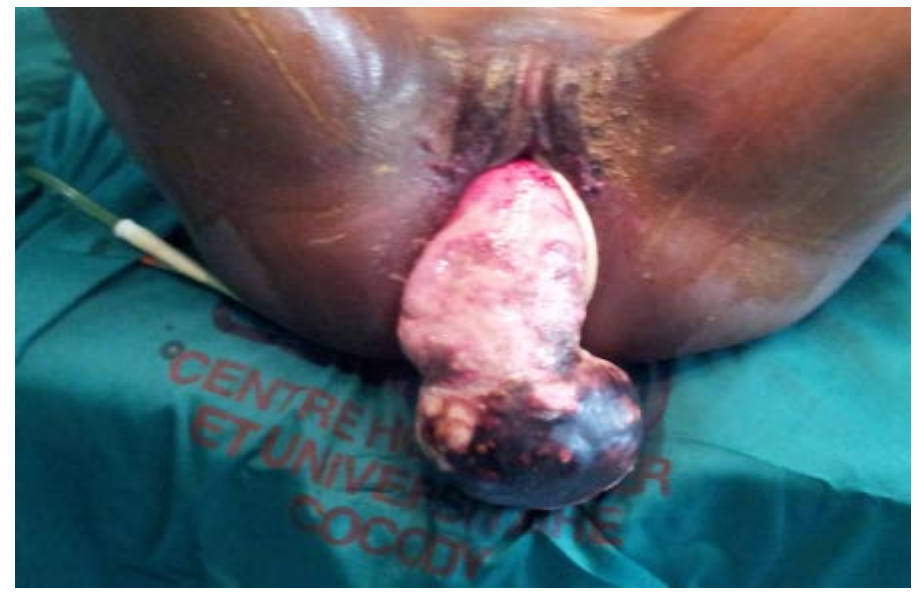

Figure 3. Reversal of non-gravid uterus due to a submucosalmyoma.

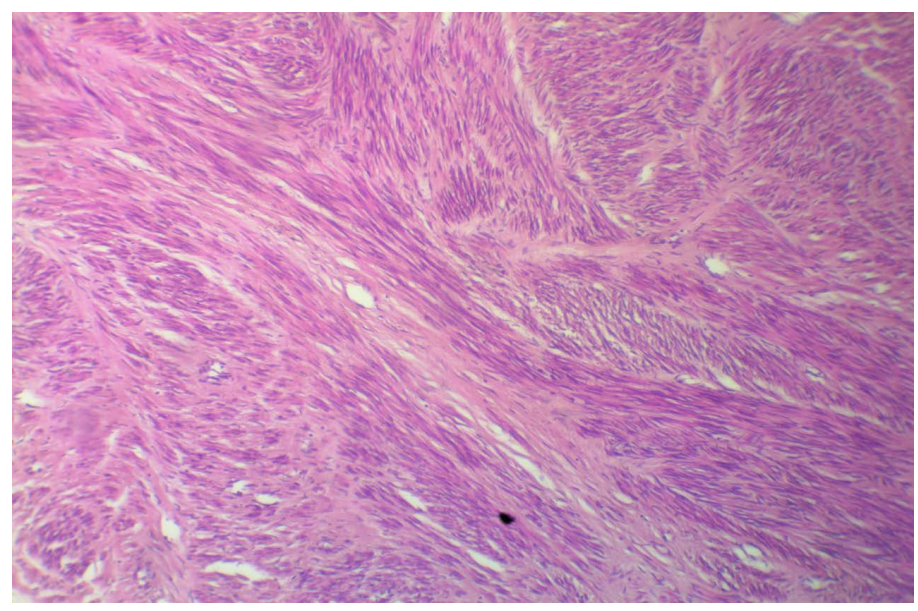

Figure 4. $(\mathrm{HE} \times 25)$ Histological examination: proliferation of myocytes in tangled beams associated fibroblasts developing collagen (cf Dr Kouamé N’da* Pathology department University.

III, the uterus is exteriorized out of the vagina. At the stage IV; the vaginal walls are involved in the turnaround. Classically, IUP occurs mainly in the primiparous and young women [5], as was the case in the first clinical observation. Fürst estimated that, into the primiparous group, uterus atone is more common due to a longer labor. According to him the placental insertion fundic site is more common [2]. In our observation, dangerous maneuvers such as excessive traction on the cord or the exaggerated uterine expression may have contributed to the occurrence of the IUP [1]. In the literature, other factors of risk are found: a fast delivery, a short umbilical cord, abnormal placental traction and uterine inertia [1] [2] [3].

In contrast, no puerperal uterine inversion (IUNP) affects older women, at least 45 years. This type of uterine inversion is most often associated with benign tumors of the uterus [8] [9] [10]. But as it is observed in young patients of childbearing age, a malignant tumor of the uterus is usually the cause. Authors such as De Vries [11] and Lupovitch [12] had reported cases. Unlike the classical 
case, the patient was young (28 years) and the newfound cause was benign uterine fibroid) in our second clinical case.

The pathophysiology of the IUNP is not yet understood. In the literature, several theories have been mentioned: a thin uterine wall, a location of the tumor to the uterine substance, a pediculated tumor, a dilation of the cervix by distension of the uterine cavity and abrupt expulsion from the tumor of the vagina [9] [13]. In our observation, the basis of implantation of the tumor was wide and located in the bottom of the uterus. Like etiology, Das found $87 \%$ of fibroids, $7 \%$ of sarcomas and $6 \%$ of carcinomas [14]. Two classifications have been proposed for the IUNP: partial or complete and acute or chronic depending on the mode of occurrence [15] [16].

\subsection{Diagnosis}

Puerperal uterine inversion (IUP) diagnosis is clinical, during delivery or immediately after, in front of three main signs that are hemorrhage, shock, and pelvic pain [1] [2] [3]. The intensity of the state of shock is not proportional to the extent of the bleeding and it can even proceed, due to an etiology not hypovolemic also neurogenetic. Indeed, the aspiration of the uterine substance through the uterine cervix caused a stretch of nervous nets of the peritoneum and the broad ligaments, as well as a compression of the ovaries [17] [18]. The treatment of IUP provides to the understanding of the physiopathology which require the correction of shock pass by the reduction of inversion associated with the recovery medical [19]. In this case, many lost times were observed before admission of the patient in our unit care. This a negative factor in the management. That was in relation with a lack of ambulance to evacuate rapidly the patients to other maternity more competent.

In the incomplete forms of the IUNP, the contribution of imagery is essential for an accurate diagnosis, for example the pelvic ultrasound and Imaging by Magnetic Resonance (MRI) [11] [12] [13]. In our Observation No. 2, the reversal was complete and easy clinical diagnosis. Indeed, the acute IUNP is characterized by a very intensive pain and more abundant menorrhagia unlike chronic forms where there is also the pelvic pain, vaginal, minimal menorrhagia. At first, it can be difficult to differentiate the IUNP to a large polyp given birth by the uterine cervix, bloody and purulent. A careful inspection will highlight the tubal orifice, the uterine cervix and the characteristic dead end [8] [9] [10]. Concerning etiologies, sub-mucosal myoma are founded in $70 \%$ to $85 \%$ of cases according to the literature [14] [15] [16]. In $15 \%$ to $30 \%$ of cases, malignant tumors were founded, mainly the uterine sarcomas. Less frequents etiologies of uterine inversion were endometrial cancer or mullerians tumors [13] [16].

\subsection{Treatment and Prognosis}

Support of IUP needs multidisciplinary actions, involving obstetrician and anesthetist. It is an emergency. Multidisciplinary treatment allows improving significantly the mother's prognosis. It combines a medical resuscitation aimed 
at correcting the shock, a quick manual reduction and antibiotic injection [20] [21]. If all methods of manual reduction fail, surgery is necessary and different techniques have been described [1] [2] [22]. Oboro [23] reported four surgical techniques: intervention by vaginal route so-called "Spinelli" which consists of a total anterior median colpohysterotomy. Laparotomy known as "Huntington technique" which consists of a light pull and continues on the round ligaments while another person trying a manual reduction vaginally; Haughty procedure which consists of a posterior median hysterotomy, facilitating the replacement of the uterus by the method of Huntington and hysterectomy as a last resort. In our case, a hysterectomy for IUP was performed after attempts failed and manual and surgical reduction before the severe hypovolemic shock, which was hardly compensated for by the 3 units globular.

Hysterectomy can be done vaginally or through high according to the habits of the operator, but also according to the conditions surgical [1] [24]. Some teams offer the laparoscopic surgery [25]. The IUP are associated with significant morbidity and maternal mortality: blood and infectious (postpartum endometritis) [5]. Immediate of IUP acute diagnosis followed to process would avoid hysterectomy [1] [4].

Several assumptions have been described in the literature in the IUNP: a conservative treatment in early forms. When there is no desire of pregnancy, or when the uterine inversion is the 3rd or 4th degree, hysterectomy remains the treatment of choice [8] [9] [10]. In the complete IUNP through abdominal hysterectomy was once the intervention of reference. Teams practice more in addition to vaginal hysterectomies [26]. Indeed, after a careful repositioning of the uterus in its anatomical position, a vaginal hysterectomy ends the procedure.

Laparoscopy and vaginal association seems to be a good alternative, to confirm the diagnosis, to assess the degree of ischemia of the annexes and the vagina, and hemostasis surgical of the uterus by laparoscopy by controlling the uterine pedicle from her origin [26] [27]. In general, the prognosis of uterine inversion is related to the precocity of diagnosis. Furthermore, obstetric prognosis is reserved for patients who have received conservative treatment, because risk of recurrence [1] [2] [5].

\section{Conclusion}

The particularity of the study is a rare clinical situation or exceptional. In its postpartum mode, we must take care of the difficulties of the expulsive phase. Some acts should not be made because they are considered as risk of factor. Preventive treatment is based on the respect of the physiology of labor. In the case of uterine inversion, the treatments without hysterectomy could be facilitated if the management is early and adequate. The limits of this study were a lack in the management of puerperal uterine inversion. For the gynecological mode, awareness of the population in order to consult earlier hospital could these situations for a better living. Furthermore, hysterectomy remains a last resort treatment in the two types, to reduce morbidity. 


\section{References}

[1] Jellab, B., Aboulfalah, A. and Abbassi, H. (2008) Hysterectomy for Uterine Inversion Puerperal: About Two Cases. Letter of Gynecologist, 332, 8-10.

[2] Ramanah, R., Maillet, R. and Riethmuller, D. (2010) Uterine Inversion Puerperale EMC, Obstetrics, 5-107-A-10.

[3] Chen, Y.L., Chen, C.A., Cheng, W.F., Huang, C.Y., Chang, C.Y., Lee, C.N. and Hsieh, C.H. (2006) Submucous Myoma Induces Uterine Inversion. Taiwanese Journal of Obstetrics and Gynecology, 45, 159-161. https://doi.org/10.1016/S1028-4559(09)60216-3

[4] Jerbi, M., Iraqui, Y., Jacob, D. and Truc, J.B. (2004) Acute Uterine Inversion Puerperale: About Two Cases. Gynécologie Obstétrique \& Fertilité, 32, 224-227. https://doi.org/10.1016/j.gyobfe.2004.01.014

[5] Goffinet, F., Heitz, D., Verspyck, E. and Philippe, H.J. (1999) Uterine Inversion Puerperale. EMC Obstetrics. Elsevier, Paris, 5-107-A-10: 1-9.

[6] Olivuzzi, M. and Del Frate, G. (2008) Acute Post Partum Uterine Inversion: Report of Two Cases. International Journal of Obstetric Anesthesia, 17, 83-85. https://doi.org/10.1016/j.ijoa.2007.03.014

[7] Lisik, F., Plonka, S., Fize, C., Calle, M. and Pennehouat, G. (2004) Rare Obstetrical Emergency: Acute Uterine Inversion Puerperale. Journal de Gynécologie Obstétrique et Biologie de la Reproduction, 33, 546-550. https://doi.org/10.1016/S0368-2315(04)96590-8

[8] Atalay, M.A., Demir, B.C., Solak, N., Atalay, F.O. and Kucukkomurcu, S. (2013) An Usual Presentation of a Submucous Leiomyoma Accounting to a Non-Puerperal Uterine Inversion: A Case Report. Journal of the Turkish-German Gynecological Association, 14, 116-118. https://doi.org/10.5152/jtgga.2013.55631

[9] Pelissier-Komorek, A., Lucereau-Barbier, M., Diab, J., Gavillon, N. and Graesslin, O. (2013) Acute Non-Puerperal Uterine Inversion of $3^{\text {rd }}$ Degree. Gynécologie Obstétrique \& Fertilité, 41, 130-132. https://doi.org/10.1016/j.gyobfe.2012.12.006

[10] Kopal, S., Seckin, N.C. and Turhan, N.O. (2001) Acute Uterine Inversion Due to a Growing Submucous Myoma in an Elderly Woman: Case Report. European Journal of Obstetrics \& Gynecology and Reproductive Biology, 99, 118-120. https://doi.org/10.1016/S0301-2115(01)00346-3

[11] De Vries, M. and Perquin, D.A.M. (2010) Non-Puerperal Uterine Inversion Due to Submucous Myoma in a Young Woman: A Case Report. Journal of Medical Case Reports, 4, 21-23. https://doi.org/10.1186/1752-1947-4-21

[12] Lupovitch, A., Edwin, R. and Ruey, C. (2005) Non-Puerperal Uterine Inversion in Association with Uterine Sarcoma: Case Report in a 26-Year-Old and Review of the Literature. Gynecologic Oncology, 97, 938-941. https://doi.org/10.1016/j.ygyno.2005.02.024

[13] Oguri, H., Maeda, N., Yamamoto, Y., Wakatsuki, A. and Fukaya, T. (2005) Non-Puerperal Uterine Inversion Associated with Endometrial Carcinoma: A Case Report. Gynecologic Oncology, 97, 973-975. https://doi.org/10.1016/j.ygyno.2005.02.023

[14] Das, P.J. (1940) Inversion of the Uterus. BJOG: An International Journal of Obstetrics \& Gynaecology, 47, 525-548. https://doi.org/10.1111/j.1471-0528.1940.tb08843.x

[15] Takano, K., Ichikawa, Y., Tsunoda, H. and Nishida, M. (2001) Uterine Inversion Caused by Uterine Sarcoma. A Case Report. Japanese Journal of Clinical Oncology, 
31, 39-42. https://doi.org/10.1093/jico/hye002

[16] Moulding, F. and Hawnaur, J.M. (2004) MRI of Non-Puerperal Uterine Inversion Due to Endometrial Carcinoma. Clinical Radiology, 59, 534-537. https://doi.org/10.1016/j.crad.2003.11.007

[17] Dayan, S.S. and Schwalbe, S.S. (1996) The Use of Small-Dose Intraveinous Nitroglycerin in a Case of Uterine Inversion. Anesthesia \& Analgesia, 82, 1091-1093.

[18] Hostetler, D.R. and Bosworth, M.F. (2000) Uterine Inversion: A Life-Threatening Obstetric Emergency. Journal of the American Board of Family Medicine, 13, 120-123. https://doi.org/10.3122/15572625-13-2-120

[19] D’Ercole, C., Shojai, R., Desbriere, R., Cravello, L. and Boubli, L. (2004) Hémorragies du post-partum immédiat: Techniques et indications de la chirurgie. Journal de Gynécologie Obstétrique et Biologie de la Reproduction, 33, 103-119. https://doi.org/10.1016/S0368-2315(04)96653-7

[20] Wendel, P.J. and Cox, S.M. (1995) Emergent Obstetric Management of Uterine Inversion. Obstetrics \& Gynecology Clinics of North America, 22, 261-274.

[21] Slaoui, M.A., Bouchikhi, C. and Banani, A. (2010) Puerperal Uterine Inversion. Revue Médicale de Liège, 65, 510-513.

[22] Achanna, S., Mohamed, Z. and Krishman, M. (2006) Puerperal Uterine Inversion: A Report of Four Cases. Journal of Obstetrics and Gynaecology Research, 32, 341-345. https://doi.org/10.1111/j.1447-0756.2006.00407.x

[23] Oboro, V.O., Akinolaa, S.E. and Apantakua, B.D. (2006) Surgical Management of Subacute Puerperal Uterine Inversion. International Journal of Gynecology \& $\mathrm{Ob}$ stetrics, 94, 126-127. https://doi.org/10.1016/j.ijgo.2006.04.037

[24] Hussain, M. (2004) Acute Puerperal Uterine Inversion. Journal of College of Physicians and Surgeons Pakistan, 14, 215.

[25] Auber, M., Darwish, B., Lefebure, A., Ness, J. and Roman, H. (2011) Management of Non-Puerperal Uterine Inversion Using a Combined Laparoscopic and Vaginal Approach. American Journal of Obstetrics \& Gynecology, 204, e7-e9. https://doi.org/10.1016/j.ajog.2011.01.024

[26] Tuckett, J.D., Yeung, A., Timmons, G. and Hughes, T. (2010) Non-Puerperal Uterine Inversion Secondary to Uterine Sarcoma and Ascites Demonstrated on CT and MRI. European Journal of Radiology Extra, 75, e119-e123. https://doi.org/10.1016/j.ejrex.2010.06.008

[27] Zhang, X., Sun, L., Chen, X. and Hua, K. (2015) Uterus Preserving Reposition of Non-Puerperal Uterine Inversion under Laparoscope: A Case Report and Literature Review. Gynecologic and Obstetric Investigation, 79, 206-209. https://doi.org/10.1159/000366475 